\title{
КОНЦЕПТУАЛЬНЫЕ МЕТОДЫ МОДЕЛИРОВАНИЯ ЗАТОПЛЕНИЯ РЕЧНЫХ ПОЙМ НА ОСНОВЕ ИХ ГЕОМЕТРИЧЕСКИХ ПАРАМЕТРОВ
}

\author{
А. А. Волчек', Д. О. Петров ${ }^{2}$ \\ ${ }^{1}$ Д. геогр. н., профессор, декан факультета инженерных систем и экологии учреждения образования \\ «Брестский государственный технический университет», Брест, Беларусь, e-mail: volchak@tut.by \\ ${ }^{2}$ K. т. н., доцент кафедры ЭВМ и систем учреждения образования \\ «Брестский государственный технический университет», Брест, Беларусь, e-mail: polegdo@gmail.com
}

\section{Реферат}

Выполнение физически обоснованного расчета динамики движения водных потоков по моделям рельефа речных пойм, построенным на основе лазерного сканирования земной поверхности с высокой разрешающей способностью, приводит значительному повышению вычислительной нагрузки на ЭВМ и временных затрат на получение прогноза области затопления речных пойм при прохождении высоких паводков и половодий.

В данной статье предлагается обзор концептуальных методов оперативного получения оценочных контуров зон затопления, возникающих во время разлива рек, оценка адекватности выполняемых расчетов и пример получаемого результата при их практическом применении.

Ключевые слова: концептуальный метод, речная пойма, затопление.

\section{CONCEPTUAL METHODS FOR SIMULATION OF RIVER FLOODPLAINS INUNDATION BASED ON THEIR GEOMETRIC PARAMETERS}

\section{Abstract}

\section{A. A. Volchak, D. O. Petrov}

Performing a physically based calculation of water flow dynamics over high resolution river floodplain elevation models, obtained by laser altimetry, leads to a significant increase in the computational load and the time spent on obtaining a forecast of inundation zones which appear as the result of high river floods.

The article offers an overview of conceptual methods targeted on obtaining a quick evaluation of possible river floodplain inundation zones, their adequacy analysis and example of practical implementation.

Keywords: conceptual method, river floodplain, inundation.

\section{Введение}

Согласно докладу Управления ООН по уменьшению опасности бедствий (UNISDR) [1] за последние двадцать лет резко, в полтора раза, возросли прямые экономические потери от бедствий, связанных с климатическими изменениями.

Статистические данные показывают, что одним из наиболее частых источников чрезвычайных ситуаций (ЧС) на территории Евразии являются наводнения, которые превосходят все остальные ЧС по площади охватываемой территории и наносимому среднему годовому ущербу [2], но поскольку полностью исключить наводнения невозможно, первоочередная задача состоит в том, чтобы максимально приспособить хозяйственную деятельность к возможным экстремальным условиям [3], и тем самым минимизировать наносимый урон.

Мониторинг паводковой ситуации и прогноз рисков наводнения это сложный комплекс задач, для решения которых требуется обработка больших объемов информации. Развитие средств дистанционного зондирования поверхности Земли, включая интенсивное применения беспилотных летательных аппаратов, привело к значительному улучшению качества трехмерных моделей местности, получаемых при помощи лазерного сканирования и фотограмметрии, что в свою очередь накладывает повышенные требования к производительности программного обеспечения математического моделирования затопления речных пойм.

Целью представленной работы является обзор происхождения и развития упрощенных концептуальных методов гидрологичского моделирования, позволяющих оперативно получать оценочные характеристики возможных областей разлива рек при паводках и половодьях.

\section{Методы расчета зон затопления}

\section{Физически обоснованный гидравлический подход}

В общем случае теоретической основой вычисления зоны затопления речной поймы является физически обоснованный расчет динамики движения водных потоков [4], которая описывается системой уравнений Сен-Венана, [5] для искомых величин $H(x, y, t), u_{x}(x, y, t)$, $u_{y}(x, y, t)$ (рисунок 1) следующим образом [6]:

$$
\begin{gathered}
\frac{\partial H}{\partial t}+\frac{\partial H u_{x}}{\partial x}+\frac{\partial H u_{y}}{\partial y}=q, \\
\frac{\partial u_{x}}{\partial t}+u_{x} \frac{\partial u_{x}}{\partial x}+u_{y} \frac{\partial u_{x}}{\partial y}=-g \frac{\partial \eta}{\partial x}+f_{x}, \\
\frac{\partial u_{y}}{\partial t}+u_{x} \frac{\partial u_{y}}{\partial x}+u_{y} \frac{\partial u_{y}}{\partial y}=-g \frac{\partial \eta}{\partial y}+f_{y},
\end{gathered}
$$

где $H$ - глубина воды, $u_{x}, u_{y}$ - горизонтальные компоненты вектора скорости течения воды, усредненные по вертикальной координате, $g$ - величина ускорения свободного падения, $\eta=H+b$-уровень свободной поверхности воды, $b(x, y)$ - высота рельефа местности, $f_{x}, f_{y}$ - горизонтальные компоненты вектора внешних и внутренних сил, действующих на слой воды.

Для вектора $\vec{f}$ имеем:

$$
\vec{f}=\overrightarrow{f f}^{\text {frict }}+\vec{f}^{\text {Cor }}+\overrightarrow{f f}^{\text {wind }}+\overrightarrow{\mathrm{f}}^{\text {visc }}
$$

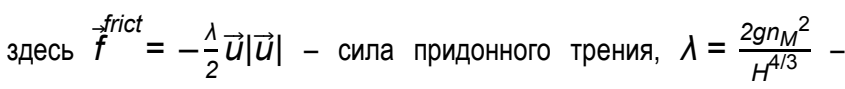
коэффициент гидравлического сопротивления, $n_{M}$ - шероховатость по Маннингу, $\vec{f}^{\text {Cor }}=2[\vec{u} \times \vec{\Omega}]-$ сила Кориолиса, $\vec{\Omega}$ - угловая скорость вращения Земли, $\vec{f}^{\text {wind }}=C_{a} \frac{\rho_{a}}{\rho H}(\vec{w}-\vec{u})|\vec{w}-\vec{u}|$ - сила ветра, $C_{a}$ - параметр, характеризующий состояние водной поверхности, $\rho_{a}$ и $\rho$ - плотность воздуха и воды соответственно, $\vec{w}$ - вектор скорости ветра в горизонтальном направлении, $\underset{f}{f}=v\left[\frac{\partial^{2} u_{x}}{\partial x^{2}}+\frac{\partial^{2} u_{y}}{\partial y^{2}}\right]-$ сила внутреннего (вязкого) трения, $\boldsymbol{V}$ - коэфффициент кинематической турбулентной вязкости. 
В уравнении непрерывности (1) присутствует параметр $q$, который характеризует скорость притока/оттока воды за счет действующих источников/стоков. Для q в общем случае имеем:

$$
q=q^{(s)}+q^{(r)}-q^{(i n f)}-q^{(e v)}
$$

где $q^{(s)}=\frac{\partial Q}{\partial S}-$ приток воды из створа реки, расположенного выше по течению, $Q(t)$ - зависимость объема поступающей воды от времени, $S$ - площадь поперечного сечения створа реки, $q^{(r)}(t)$ - приток воды, обусловленный осадками, $q^{(\text {inf })}(x, y, t)$ и $q^{(e v)}(t)$ - отток воды за счет инфильтрации в почву и испарения соответственно. Указанные источники/стоки зависят от температуры воздуха, температуры воды, влажности воздуха, облачности, глубины промерзания почвы, насыщенности влагой грунта и его температуры.

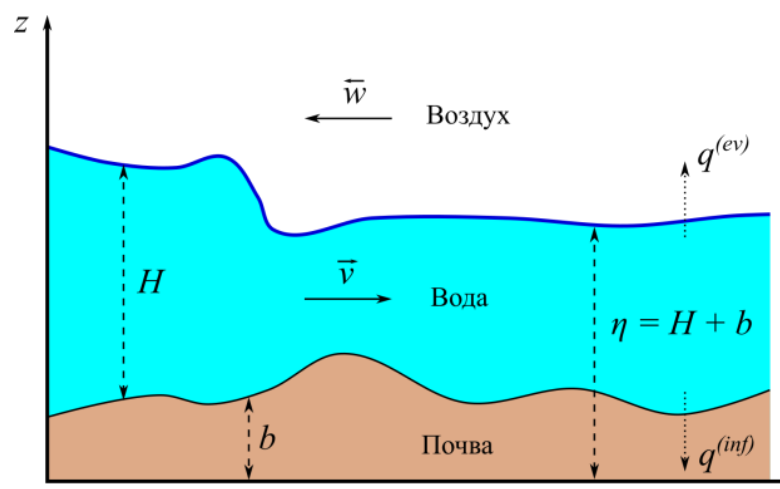

Рисунок 1 - Величины, используемые в гидравлической модели динамики движения водных потоков [6]

Преимуществом двумерного гидравлического подхода к прогнозированию разлива воды по речной пойме при прохождении наводнений является возможность получения распределения скоростей движения поверхностных водных потоков по всей площади возникающей зоны затопления, что, однако, достигается за счет значительных вычислительных затрат и необходимости проводить регулярные гидрологические изыскания для получения информации о характеристиках поверхности рельефа речных долин, гидрологических зависимостях и др [7].

Для численного решения системы уравнений (1)-(3) требуется функция $b(x, y)$, связывающая координаты точек, покрывающих пойму реки на плоскости карты с их высотами. Такая функция называется цифровой моделью рельефа (ЦМР) и представляет собой способ организации множества высотных отметок и метод интерполяции высот промежуточных точек [8].

Источниками исходных данных для создания цифровых моделей рельефа служат как топографические карты, так и результаты дистанционного зондирования поверхности Земли. К соответствующим техническим средствам ДЗЗ относят радиолокаторы с синтезированной апертурой (РСA), интерферометрические радиолокаторы с синтезированной апертурой (ИРСА) как воздушного, так и космического базирования и лидары исключительно воздушного базирования.

Задача восстановления трехмерной поверхности на основе множества высотных отметок в узлах нерегулярной сети в большинстве случаев решается путем построения триангуляции Делоне для набора вершин - вершины соединяются серией ребер и формируют нерегулярную триангуляционную сеть (TIN) (см. рисунок 2) $[9,10]$.
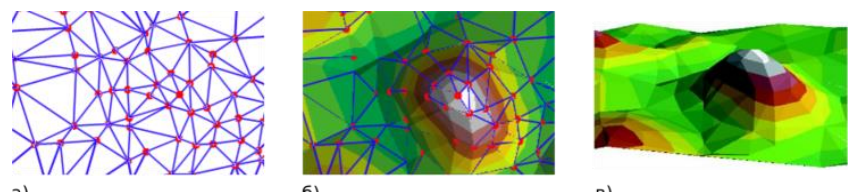

a)

а - вершины и ребра нерегулярной сети,

б - треугольные грани модели трехмерной поверхности, в - модель поверхности рельефа местности

Рисунок 2 - Представление модели поверхности рельефа местности нерегулярной триангуляционной сетью $[9,10]$
При построении модели рельефа земной поверхности по набору высотных отметок, расположенных в узлах прямоугольной матрицы, можно выделить два подхода: согласно первому - элементы матрицы интерпретируются как независимые друг от друга дискретные горизонтальные площадки с заданным значением высоты (смотреть рисунок 3, a), а согласно второму - между соседними узлами производится интерполяция значений высоты (смотреть рисунок 3, б) [11].
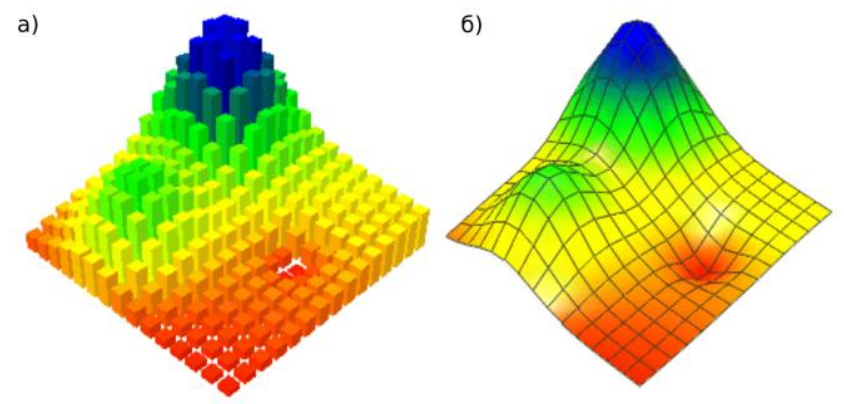

Рисунок 3 - Способы вычисления высот между соседними узлами прямоугольной матрицы [11]

К достоинствам нерегулярных триангуляционных сетей при создании моделей фррагментов земной поверхности можно отнести как однозначность вычисления высоты рельефа между любыми тремя узлами TIN, так и лучшее представление сильнопересеченной местности. При использовании нерегулярных триангуляционных сетей проявляются следующие их недостатки: сложная организация необходимой структуры данных и необходимость перерасчета триангуляции при каждом изменении рельефа моделируемой территории.

В отличие от TIN-модели, регулярное расположение узлов прямоугольной матрицы приводит к неоднозначности вычисления высот между ними, благодаря существованию множества вариантов построения интерполяционной поверхности между соседними вершинами $[11,12]$. Даже простейший способ триангуляции четырехугольной трехмерной грани путем соединения ребром двух противоположных вершин приводят к созданию двух вариантов поверхности с разной формой: построение ребра AЕ формирует вогнутую триангуляционную поверхность между вершинами $A, B, E, D$ (см. рисунок 4, а), а построение ребра $\mathrm{BD}$ формирует выпуклую поверхность между теми же вершинами (см. рисунок 4, б).

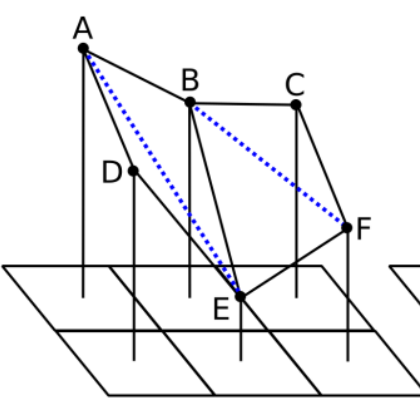

a)

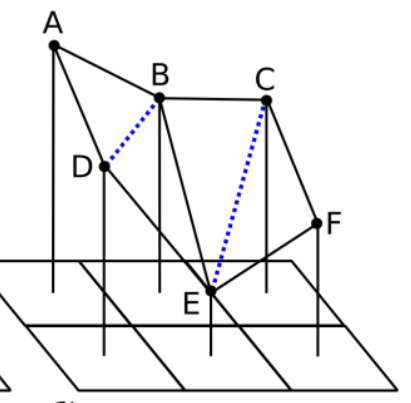

6)
Рисунок 4 - Изменение формы триангуляционной поверхности между четырьмя соседними вершинами при построении ребер между двумя разными парами противоположных вершин

Способы упрощения гидравлической модели и их обоснование Использование двумерной системы уравнений Сен-Венана для моделирования распространения воды по рельефу местности в первую очередь актуально для случаев разрушения гидротехнических сооружений [13] и для расчета движения волны паводка в долинах горных рек. В случаях, когда процесс является медленно изменяющимся, для расчета установившейся динамики движения водного потока в русле реки оправдано использование одномерной системы уравнений Сен-Венана [14] (при этом не учитывается центробежный эффект движения воды по изгибу русла реки, а свободная 
Вестник Брестского государственного технического университета. 2021

поверхность воды считается горизонтальной в каждом поперечном сечении речного русла). Поэтому одним из наиболее популярных подходов к моделированию речной гидравлики в широко известных прикладных гидрологических системах, таких как MIKE 11 и HEC-RAS, является решение конечно-разностным методом одномерных уравнений Сен-Венана для участков речных пойм [15]. Результатом решения является усредненная по глубине скорость движения водь и высота ее подъема на каждом из поперечных сечений, а искомая зона затопления рассчитывается путем построения геометрической модели поверхности воды в пойме реки и наложения ее на соответствующую цифровую модель рельефа [5].

\section{Концептуальные подходы к вычислению контуров зонь затопления}

Подход к вычислению контуров зоны затопления, предполагающий создание трехмерной модели водной поверхности и последующее ее пересечение с ЦМР для определения контура границы области затопления (см. рисунок 5) $[16,17,18,15]$, представляет собой замену физически обоснованной модели растекания воды по рельефу местности упрощенной концептуальной моделью. Используемые в такой геометрической задаче данные об уровне воды могут быть либо расчетными (например, полученными на основе гидравлических моделей), либо эмпирическими (полученными в результате гидрологических измерений, выполненных в контрольных точках русла). Вследствие геометрического характера решаемой задачи получаемый результат зависит в том числе и от геометрических параметров речной поймы.

В ряде случаев в качестве модели поверхности воды можно использовать горизонтальную плоскость, если разницы высотных отметок урезов воды меньше высотной точности ЦМР [19, 20, 21, 15]. При значительном перепаде уровней воды между соседними измерительными гидрологическими постами для моделирования поверхности воды необходимо использовать наклонную плоскость $[22,23,24,25,26]$

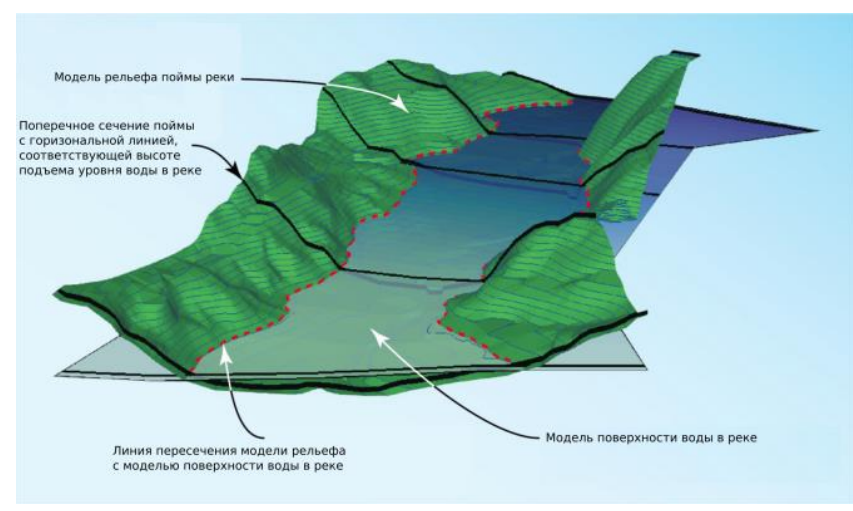

Рисунок 5 - Принцип геометрического расчета контуров зоны затопления речной поймы [15, с. 105]

Применение пересечения плоскости с ЦМР для расчета зоны затопления достаточно ограничено и используется как для отдельных участков реки, расположенных между соседними постами измерения уровня подъема воды, так и при моделировании затопления прибрежных участков водохранилищ, озер, морей и океанов $[27,28]$.

Наиболее широко используемым геометрическим методом расчета границ области затопления речных пойм является метод створов. В методе створов поверхность поднявшейся воды представлена трехмерной сеточной триангуляционной моделью, построенной между последовательно расположенными горизонтальными ломаными линиями [29], пересекающими осевую линию реки на высоте, равной прогнозируемому либо фактическому уровню подъема воды на соответствующих поперечных сечениях поймы реки (см. рисунок 6) $[16,15,22,23,24,30,31,32]$.

Известен алгоритм вычисления контуров зоны затопления поймы бесприточного участка реки, базирующийся на методе створов, преимуществом которого является возможность работы на мобильных вычислительных платформах, существенно ограниченных в вычислительных ресурсах [33, 34].

Поднявшаяся вода представлена полосой криволинейной поверхности, состоящей из смежных треугольных граней и построенной методом движения образующей по модели осевой линии реки. Ширина полосы соответствует предполагаемой ширине разлива реки во время наводнения. Модель осевой линии реки представлена ломаной, соединяющей проекции гидрологических постов наблюдения на ось русла реки, вертикальные координаты которых соответствуют высоте подъема уровня воды. Расчет зоны затопления предусматривает предварительную растеризацию граней модели поверхности поднявшейся воды в соответствии с разрешением ЦМР поймы реки в виде высотных отметок в узлах регулярной сети. Зона затопления рассчитывается путем распространения вычисленных во время растеризации высот элементов треугольных граней модели поднявшейся воды выполнением рекурсивного алгоритма заливки элементов матрицы ЦМР с «затравкой», расположенной в вершинах модели осевой линии реки (см. рисунок 7, а): если расчетная высота подъема воды превышает высоту соответствующего элемента ЦМР, то таковой элемент модели рельесра считается затопленным (см. рисунок 7, б). При невозможности затопления очередных элементов ЦМР расчет зоны затопления считается завершенным.

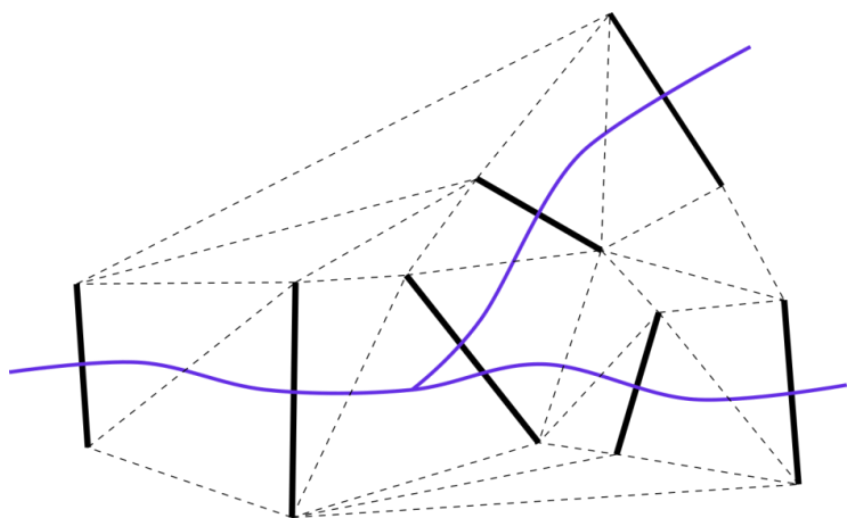

Рисунок 6 - Сеточная триангуляционная поверхность между поперечными сечениями поймы реки

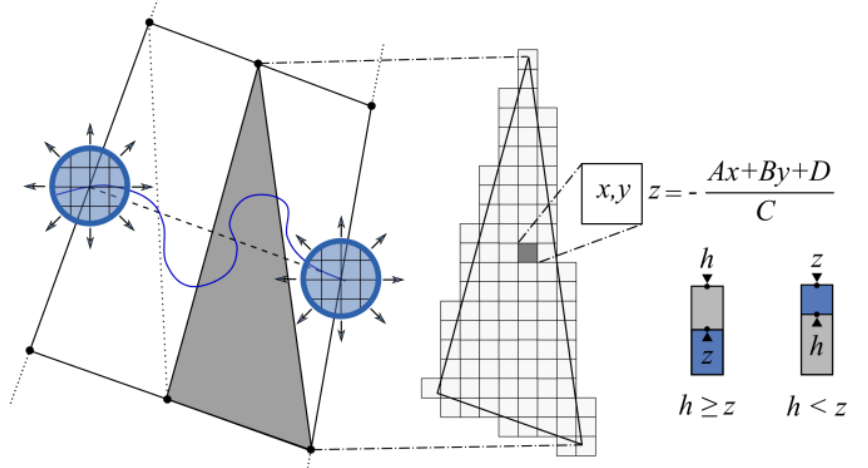

a)

б)

а - распространение вычисленных высот элементов треугольных граней модели поднявшейся воды по ЦМР; б - определение факта затопления отдельных элементов ЦМР

Рисунок 7 - Расчет зоны затопления поймы бесприточного участка реки

Существует возможность исключить необходимость построения трехмерной сеточной триангуляционной модели поверхности воды путем непосредственного вычисления высоты уровня поднявшейся воды для элементов ЦММР, расположенных между соседними 
гидрологическими постами наблюдения. Расчет высоты уровня поднявшейся воды выполняется следующим образом:

$$
h=\min \left(h_{1}, h_{2}\right)+\frac{d_{1}}{d_{1}+d_{2}} / h_{1}-h_{2} /,
$$

где $h$ - искомая высота уровня воды, $h_{1}$ - высота уровня воды на первом гидрологическом посту, $h_{2}$ - высота уровня воды на втором гидрологическом посту, $d_{1}$ и $d_{2}$ - расстояния элемента ЦМР от поперечных сечений речной поймы, проходящих через соседние гидрологические посты наблюдения (см. рисунок 8) [32].

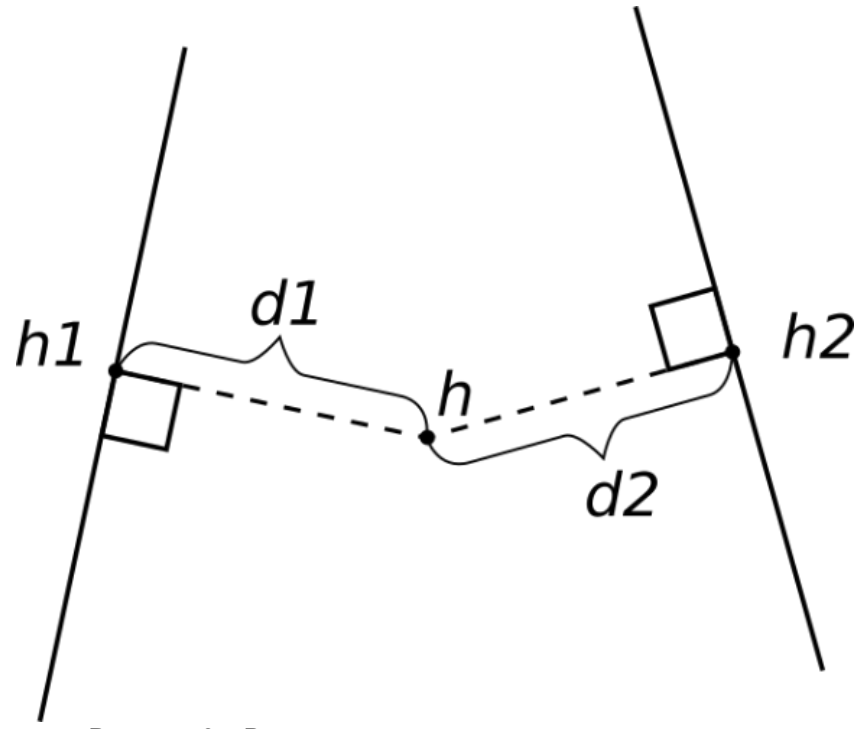

Рисунок 8 - Расчет высоты подъема уровня воды между соседними гидрологическими постами наблюдения

Перспективным направлением в рамках геометрического подхода к построению области затопления при прохождении паводков на реках является имитация непосредственно распространения воды по цифровой модели рельефа поймы реки, примером которого является алгоритм, предложенный в работе [35]. Указанный алгоритм моделирует обратное распространение воды вверх по течению реки по условным горизонтальным плоскостям, находящимся на расчетной высоте каждого элемента растровой развертки осевой линии водотока (см. рисунок 9) с последующим объединением частных зон затопления, лежащих на разных плоскостях, в общую ступенчатую фигуру.

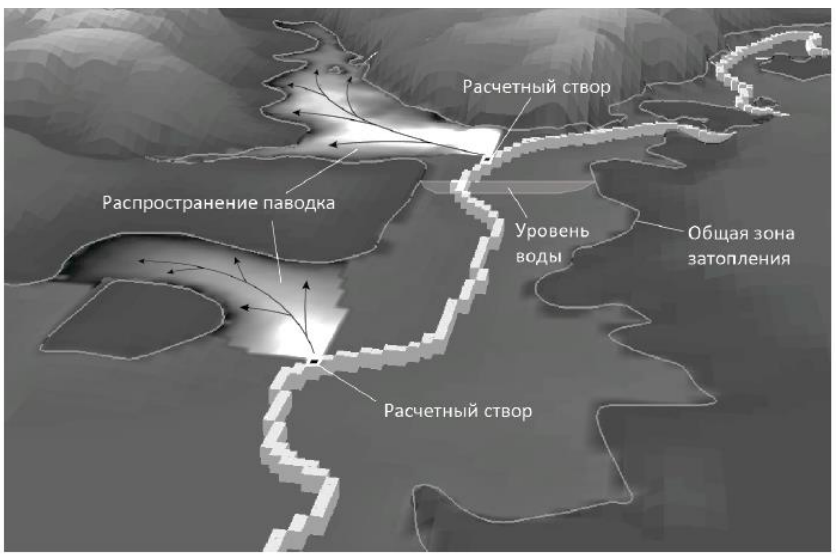

Рисунок 9 - Моделирование распространения воды по растру ЦМР вверх по течению водотока [35, с. 55]

Дальнейшим развитием упомянутого подхода является следующий алгоритм, предполагающий применение клеточного автомата для распространения воды по ЦМР поймы речной сети (см. рисунок 10) [36].

На первом этапе выполняется преобразование в растр проекций осевых линий рек на ЦМР поймы речной сети в виде высотных отметок $r_{x y} \in R$ в узлах регулярной сети, а также создается список $W$, содержащий водотоки речной системы, отсортированные по возрастанию их рангов (каждый элемент $w_{i} \in W$ представляет собой список $A_{w}$, элементы которого принадлежат осевой линии $i$-го водотока). Высоты элементов разложения в растр $a_{i} \in A_{w}$ проекций осевых линий рек вычисляются путем линейной интерполяции высот подъема уровня воды $h\left(g_{i}\right)$ на гидрологических постах наблюдения $g_{i} \in G$, при этом все элементы ЦМР поймы, расположенные под проекциями осевых линий, считаются затопленными. На втором этапе работы алгоритма выполняется распространение интерполированных вдоль осевых линий русел высот подъема уровня воды по ЦМР при помощи двумерного клеточного автомата $K$. С каждым связаны следующие свойства: $r\left(k_{x y}\right)$ - значение элемента с совпадающими координатами, $v\left(k_{x y}\right)$ - высота уровня воды над соответствующим элементом $r_{x y} \in R$. Если $r_{x y} \in R$ затоплен, то значение $v\left(k_{x y}\right)$ положительно, в противном случае $v\left(k_{x y}\right)=-1$. Вводится параметр линейной интерполяции $t$, которому перед началом итераций КА присваивается значение из промежутка $[0,1]$. Правило синхронного изменения состояния ячеек $k_{x y} \in K$ задается следующим

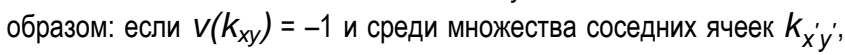
находящихся в окрестности Мура относительно $k_{x y}$ есть положительные значения $v\left(k_{x^{\prime} y^{\prime}}\right)$, то обозначив через $h$ результат линейной интерполяции с параметром $t$ между минимальной и максимальной положительной величиной $v\left(k_{x^{\prime} y^{\prime}}\right)$ среди множества $k_{x^{\prime} y^{\prime}}$ и в случае справедливости неравенства $h>r\left(k_{x y}\right)$ новым значением $v\left(k_{x y}\right)$ станет величина $h$. Условием завершения работы клеточного автомата (КА) и соответственно окончания процесса моделирования распространения фронта поверхности воды является отсутствие изменений своего состояния ячейками КА. Искомой зоной затопления является множество $\left\{k_{x y}: v\left(k_{x y} \in K\right)>-1\right\}$.

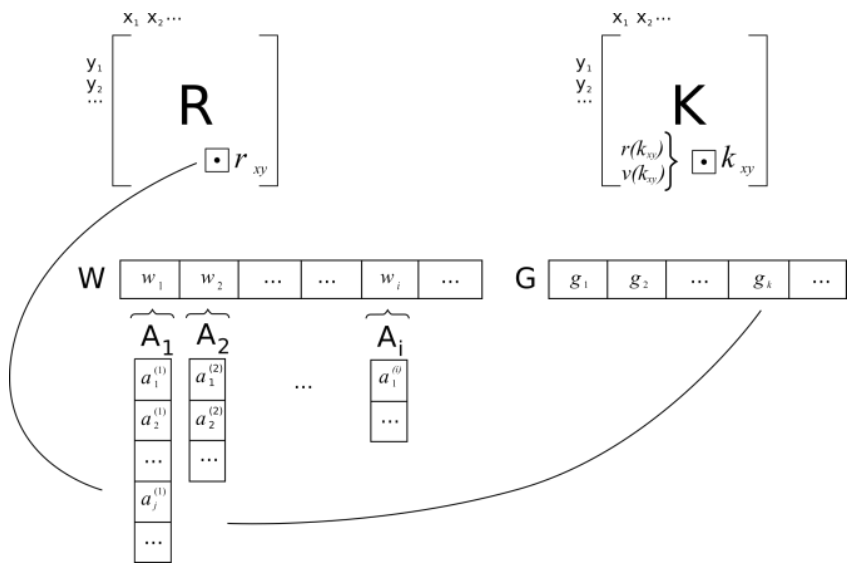

Рисунок 10 - Представление данных в алгоритме расчета затопления речной сети, использующего клеточный автомат

В качестве примера практического использования описанного алгоритма можно привести моделирование зоны затопления окрестностей г. Каменца на участке р. Лесной между д. Бабичи и д. Голый Борок 05.06.2017, которое позволило дать научное обоснование мероприятий по снижению вероятности возникновения заморных явлений в пойме реки (см. рисунок 11).

Достоинством разработанного алгоритма по отношению к известным геометрическим методам расчета зоны затопления поймы участков речной сети следует считать отсутствие необходимости прибегать к сложным построениям геометрического сопряжения моделей поверхности воды, относящихся к разным водотокам и позволяет регулировать ширину моделируемого разлива воды подбором значения параметра линейной интерполяции $t$. 
Вестник Брестского государственного технического университета. 2021

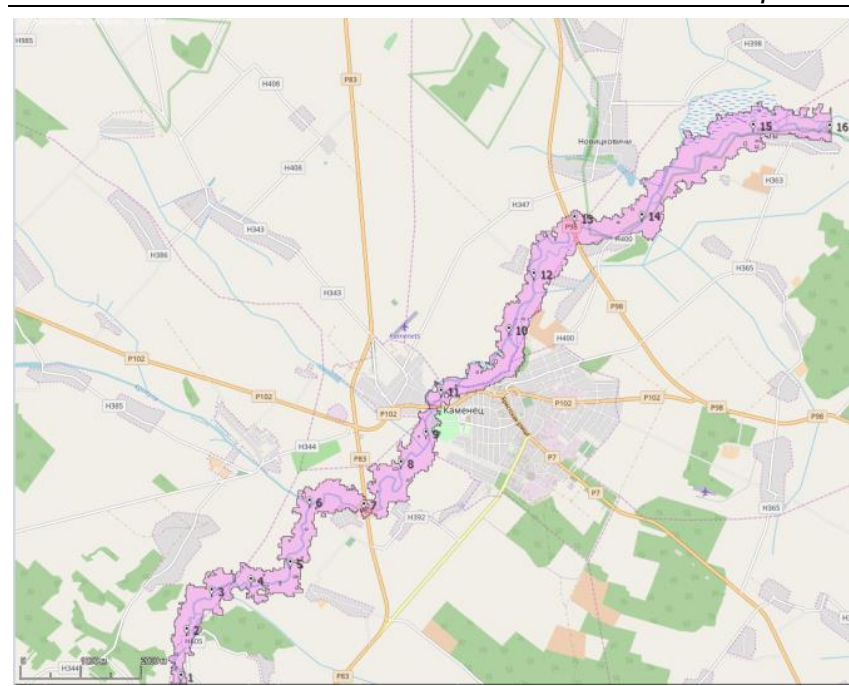

Рисунок 11 - Результаты моделирования затопления окрестностей г. Каменца на участке р. Лесной между д. Бабичи и д. Голый Борок 05.06.2017

\begin{abstract}
Анализ адекватности концептуальных подходов к расчету зоны затопления

Для алгоритмов, предложенных в работах [33, 34, 36], выполнен анализ адекватности на основе использования набора данных «EMSR044: Floods in Germany» (http://emergency.copernicus.eu/ mapping/list-of-components/EMSR044), содержащего карты затопления, возникшего 03.06.2013 во время прохождении дождевого паводка, окрестностей ряда населенных пунктов, расположенных вдоль течения р. Эльбы на территории Федеративной Республики Германия, и ЦLMP EU-DEM v 1.0 (https://land.copernicus.eu/pan-european/satellitederived-products/eu-dem/view). В результате проведенного анализа получены высокие величины коэффициента подобия расчетных зон затопления фактически зарегистрированным: от 0,76 до 0,81 при среднем значении коэффициента пересеченности местности $\geq 0,6$ м и от 0,37 до 0,44 при среднем значении коэффициента пересеченности местности менее 0,6 м [37].

Определение степени подобия расчетной зоны затопления фактически зарегистрированной применен критерий $F=\frac{|\mathrm{A} \cap \mathrm{B}|-|\mathrm{B} \backslash \mathrm{A}|}{|\mathrm{A} \cap \mathrm{B}|+|\mathrm{A}| \mathrm{B}|+| \mathrm{B} \backslash \mathrm{A} \mid}[25]$, где $A-$ множество элементов ЦМР, находящихся в действительной зоне затопления, а $B$-в расчетной.
\end{abstract}

\section{Заключение}

Среди методов вычисления прогнозируемой зоны затопления окрестностей речного русла возможно выделить отдельное подмножество концептуальных подходов, использующих геометрические параметры рельефра речных пойм. К достоинствам рассмотренных подходов относятся нетребовательность к вычислительным ресурсам, удовлетворительное качество прогнозирования области затопления при наличии густой сети гидрологических постов и при недоступности гидродинамических характеристик речной долины. К недостаткам можно отнести следующие три [16]: чрезмерно упрощение гидрологических и гидродинамических процессов, ограничение расчета области шириной поперечных сечений речной долины, нетривиальность выбора и расположения данных сечений (особенно при необходимости вычисления затопления речной системы).

\section{Список цитированных источников}

1. Economic Losses, Poverty\& DISASTERS. 1998-2017 // United Nations Office for Disaster Risk Reduction Analysis [Электронный реcypc]. - 2017. - Режим доступа: https://www.unisdr.org/2016/iddr/IDDR2018_Economic\%20Losses.pdf. - Дата доступа: 02.03.2021.

2. Мухин, В. И. Типизация источников чрезвычайных ситуаций гидрологического характера / В. И. Мухин, В. Л. Шимитило // Научные и образовательные проблемы гражданской защиты. - 2010. № 2. - C.70-73.

3. Петров, Д. О. Программный модуль анализа накопления снега для системы мониторинга и прогнозирования паводка / Д. О. Петров // Вестник БрГТУ. - 2014. - № 2 (86): Серия водохозяйственное строительство, теплоэнергетика и геоэкология. - С. 134-137.

4. Геоинформационная система для прогноза сезонных затоплений / И. А. Кобелев, А. В. Писарев, С. С. Храпов, А. В. Хоперсков // «ИнтерКарто-ИнтерГИС 17». Устойчивое развитие территорий: теория ГИС и практический опыт : материалы междунар. конф., Белокуриха, Денпасар, 14 - 19 декабря 2011 г. / Институт водных и экологических проблем СО РАН. - Барнаул, 2011. - С. 190-197.

5. Дьяконова, Т. А. Численная гидрологическая модель весеннего затопления для территории Волго-Ахтубинской поймы: анализ эффективности двухступенчатого гидрографра / Т.А. Дьяконова // International Journal of Open Information Technologies. - 2017. № 12. - C. 54-59.

6. Дьяконова, Т. А. Компьютерное моделирование динамики затопления территорий в случае чрезвычайных ситуаций с использованием технологий параллельных вычислений / Т. А. Дьяконова, А. В. Хоперсков, С. С. Храпов // Кибернетика и программирование. - 2016. - №. 3. - С. 17-34.

7. Bates, P. D. A simple raster-based model for flood inundation simulation / P. D. Bates, A. P. J. De Roo // Journal of hydrology. - 2000. Vol. 236 (1). - P. 54-77.

8. Малявский, Б. К. Методы цифрового моделирования рельефа земной поверхности / Б. К. Малявский, А. А. Жарновский // Геодезия и картография. - 1974. - № 6. - С. 31-38.

9. Что такое TIN поверхность? // Справочная система ArcGIS Desktop [Электронный ресурс]. - 2017. - Режим доступа: http://desktop.arcgis.com/ru/arcmap/10.3/manage-data/tin/fundamentals-of-tin-surfaces.htm. - Дата доступа : 02.06.2017.

10. The essentials of a TIN model [Электронный ресурc] // Introduction to Spatial Analysis. - 2017. - Режим доступа: http://planet.botany.uwc.ac.za/nisl/GIS/spatial/chap_1_50.htm. - Дата доступа: 02.06.2017.

11. What's the point? Interpolation and extrapolation with a regular grid DEM [Электронный ресурс] // GeoComputation 99. - 1999. - Режим доступа: http://www.geocomputation.org/1999/082/gc_082.htm. Дата доступа: 03.06.2017.

12. Цифровая модель рельефа [Электронный ресурс] // LidarWiki. 2015. - Режим доступа: http://lidar.pro/wiki/Циифровая_модель_рельефра. - Дата доступа : 03.06.2017.

13. Еремин, М. А. Компьютерная модель прорыва Волжской плотины / М. А. Еремин, А. В. Хоперсков // Вестник ВолГУ. Серия 1: Математика. Физика. - 2006. - № 10. - С. 139-142.

14. Карепова Е. Д. Моделирование неустановившегося движения воды в нижнем бьефе Богучанской ГЭС / Е. Д. Карепова, Г. А. Федоров // Вычислительные технологии. - 2008. - № S2. C. $28-38$

15. Federal Guidelines for Inundation Mapping of Flood Risks Associated with Dam Incidents and Failures [Электронный ресурc] // FEMA. 2013. - Режим доступа: https://www.fema.gov/media-librarydata/96171edb98e3f51ff9684a8d1f034d97/Dam_Guidance_508.pdf. Дата доступа : 12.02.2017.

16. Петров, Д. О. Алгоритм вычисления границ области затопления для речной сети с моделированием распространения воды по растровому представлению рельефа / Д. О. Петров, А. А. Волчек, Д. А. Костюк // Доклады БГУИР. - 2016. - № 5 (99) - С. 73-78.

17. К вопросу моделирования и прогнозирования паводковой ситуации на мелиорированных землях / Д. О. Петров, А. А. Волчек, Д. А. Костюк, Н. Н. Шешко // Экологическое состояние природной среды и научно-практические аспекты современных мелиоративных технологий: сб. науч. тр. / ФГБОУ ВПО РГАТУ. - Рязань, 2012. - Вып. 5. - С. 112-116.

18. Автоматизированная визуализация паводковой ситуации / Д. О. Петров, А. А. Волчек, Д. А. Костюк, Н. Н. Шешко // Прыроднае асяроддзе Палесся: асаблівасці і перспектывы развіцця: 
Вестник Брестского государственного технического университета. 2021

зб. навук. прац / Палескі аграрна-экалагічны інстытут НАН Беларусі. - Брэст: Альтернатива, 2013. - Вып. 6. - С. 5-7.

19. Геоинформационный анализ последствий катастрофических наводнений по материалам ДЗЗ / Б. А. Новаковский, О. Н. Колесникова, А. И. Прасолова, Р. В. Пермяков // Геоматика. - 2015. № 2. - C. 52-56.

20. Guerin, S. Methodology used to determine coastal flooding due to sea level rise / S. Guerin, J. Thorp, N. Thompson // A Coastal Impact Study: Nation Under Siege. - 2007. - P. 25-31.

21. Assessment of inundation risk from sea level rise and storm surge in northeastern coastal national parks / A. Murdukhayeva, P. August, M. Bradley, C. LaBash, N. Shaw // Journal of Coastal Research. 2013. - Vol. 29. - № 6a. - P. 1-16.

22. Постнова, И. С. Технология оценки с помощью ГИС зон затопления весенними паводками малой обеспеченности / И. С. Постнова, С. Г. Яковченко, В. О. Дмитриев // Вычислительные технологии специальный выпуск: труды международной конференции и школы молодых ученых "Вычислительно-информационные технологии для наук об окружающей среде" (CITES 2005), Томск, 13-23 марта 2005 г. : в 2 ч. - Томск, 2005. - Ч. 2. - Т. 10. - С. 39-46.

23. Опыт прогноза зон затопления при паводках и наводнениях । С. В. Серебряков, А. Н. Гущин, М. Е. Коршунов, В. В. Гусев // Геопрофи. - 2005. - № 5. - С. 53-55.

24. Серебряков, С. В. Опыт создания геоинформационной системы управления рисками чрезвычайных ситуаций в Свердловской области / С. В. Серебряков, В.В.Гусев, Ю.Д.Зраенко // Вестник СГУГиТ (Сибирского государственного университета геосистем и технологий). - 2010. - № 1 (12). - С. 139-144.

25. Horritt, M. S. A methodology for the validation of uncertain flood inundation models / M.S. Horrit //Journal of Hydrology. - 2006. - Vol. 326, № 1. - P. 153-165.

26. Алсынбаев, К. С. Разработка интегрированной системы мониторинга и прогнозирования ледовой и паводковой обстановки на реках автономного округа на основе оперативных данных ДЗ3 и гидропостов / К. С. Алсынбаев, Я. С. Суляев // Югорский научноисследовательский институт информационных технологий: отчет за 2007 год. - Новосибирск : Изд-во СО РАН, 2008. - С. 35-39.

27. Вишневская, И. А. Компьютерная технология оценки зон затопления при наводнениях: автореф. дис. ... канд. технич. наук: 05.11.13 / И. А. Вишневская; Ин-т прикладной геофизики им. ак. Е. К. Федорова. - М., 2006. - 23 с.

28. Mapping Coastal Inundation Primer // NOAA Coastal Services Center [Электронный ресурс]. - 2012 - Режим доступа: https://coast.noaa.gov/digitalcoast/_/pdf/guidebook.pdf. - Дата доступа : 21.05.2016.

29. Скворцов, А. В. Алгоритмы построения триангуляции с ограничениями / А. В. Скворцов // Вычислительные методы и программирование. - 2002. - Т. 3. - № 3. - С. 82-92.

30. HEC-RAS River Analysis System. User's Manual. Version 5.0 G. W. Brunner // US Army Corps of Engineers Hydrologic Enginnering Center [Электронный ресурс]. - 2016. - Режим доступа: http://www.hec.usace.army.mil/software/hec-

ras/documentation/HEC-RAS\%205.0\%20Users\%20Manual.pdf. Дата доступа : 19.05.2016.

31. Early Warning And On-Line Mapping For Flood Events / D. Mioc, B. Nickerson, F. Anton, E. MacGillivray, A. Morton, D. Fraser, P. Tang, A. Kam // Geoscience and Remote Sensing, New Achievements / ed. by D. Riccio, P. Imperatore. - INTECH Open Access Publisher, 2010. - Ch. 9. - P. 147-162.

32. Flood simulation and visualization / M. Kollinger, K. Vondráček, V. Šeblová, J. Zdražil, J. Jirka, L. Vokounová // Central European Seminar on Computer Graphics. Slovakia. - 2003.

33. Модуль расчета затопления территории для системы мониторинга и прогнозирования паводка / Д. О. Петров, А. А. Волчек, Д. А. Костюк, Н. Н. Шешко // Вестник БрГТУ. Серия физика, математика, информатика. - 2011 . - №5 (71). - С. 43-45.

34. Геометрична візуалізація зони затоплення для системи моніторингу і прогнозування паводку / Д. О. Петров, В.В.Вишнівський,
О. О. Волчек, Д. О. Костюк // Телекомунікаційні та інформаційні технології. - 2016. - №2. - С. 27-32.

35. Визуализация гидрологической обстановки в бассейнах крупных рек средствами ГИС-технологий / С. В. Борщ, Т. Е. Самсонов, Ю. А. Симонов, Е. А. Львовская // Труды Гидрометеорологического научно-исследовательского центра Российской Федерации. - 2013. - № 349. - С. 47-62.

36. Система расчета и визуализация зоны затопления на основе клеточного автомата / Д. О. Петров, А. А. Волчек, Д. А. Костюк, Н. Н. Шешко // Актуальные проблемы наук о Земле: использование природных ресурсов и сохранение окружающей среды: сб. материалов междунар. науч.-практ. конф., посвящ. году науки в Респ. Беларусь: в 2 ч., Брест, 25 - 27 сент. 2017 г. / Ин-т природопользования НАН Беларуси, Брест. гос. ун-т им. А. С. Пушкина, Брест. гос. техн. ун-т ; редкол.: А. К. Карабанов [и др.] ; науч. ред. А. К. Карабанов, М. А. Богдасаров. - Брест: БрГУ, 2017. - 4. 1. - C. $145-148$.

37. Петров, Д. О. Оценка адекватности применения геометрических методов для построения зоны затопления пойм равнинных рек / Д. О. Петров, А. А. Волчек // Туристический и природный потенциал водных объектов белорусско-польского пограничья: материалы науч.-практ. консреренции (Брест, 30-31 октября 2020 года) / гл. ред. Н. В. Михальчук - Брест : Альтернатива, 2020. - С. 127-130.

\section{References}

1. Economic Losses, Poverty\& DISASTERS. 1998-2017 // United Nations Office for Disaster Risk Reduction Analysis [Elektronnyj resurs]. 2017. - Rezhim dostupa: https://www.unisdr.org/2016/-iddr/IDDR2018_Economic\%20Losses.pdf. - Data dostupa : 02.03.2021.

2. Muhin, V. I. Tipizaciya istochnikov chrezvychajnyh situacij gidrologicheskogo haraktera / V. I. Muhin, V. L. SHimitilo // Nauchnye i obrazovatel'nye problemy grazhdanskoj zashchity. - 2010. - № 2. - S.70-73.

3. Petrov, D. O. Programmnyj modul' analiza nakopleniya snega dlya sistemy monitoringa i prognozirovaniya pavodka / D. O. Petrov // Vestnik BrGTU. - 2014. - № 2 (86): Seriya vodohozyajstvennoe stroitel'stvo, teploenergetika i geoekologiya. - S. 134-137.

4. Geoinformacionnaya sistema dlya prognoza sezonnyh zatoplenij / I. A. Kobelev, A. V. Pisarev, S. S. Hrapov, A. V. Hoperskov // «InterKarto-InterGIS 17». Ustojchivoe razvitie territorij: teoriya GIS i prakticheskij opyt: materialy mezhdunar. konf., Belokuriha, Denpasar, 14 - 19 dekabrya $2011 \mathrm{~g}$. / Institut vodnyh i ekologicheskih problem SO RAN. Barnaul, 2011. - S. 190-197.

5. D'yakonova, T. A. CHislennaya gidrologicheskaya model' vesennego zatopleniya dlya territorii Volgo-Ahtubinskoj pojmy: analiz effektivnosti dvuhstupenchatogo gidrografa / T. A. D'yakonova // International Journal of Open Information Technologies. - 2017. - № 12. - S. 54-59.

6. D'yakonova, T. A. Komp'yuternoe modelirovanie dinamiki zatopleniya territorij v sluchae chrezvychajnyh situacij $s$ ispol'zovaniem tekhnologij parallel'nyh vychislenij / T. A. D'yakonova, A. V. Hoperskov, S. S. Hrapov // Kibernetika i programmirovanie. - 2016. - №. 3. - S. 17-34.

7. Bates, P. D. A simple raster-based model for flood inundation simulation / P. D. Bates, A. P. J. De Roo // Journal of hydrology. - 2000. Vol. 236 (1). - P. 54-77.

8. Malyavskij, B. K. Metody cifrovogo modelirovaniya rel'efa zemnoj poverhnosti / B. K. Malyavskij, A. A. ZHarnovskij // Geodeziya i kartografiya. - 1974. - № 6. - S. 31-38.

9. CHto takoe TIN poverhnost'? // Spravochnaya sistema ArcGIS Desktop [Elektronnyj resurs]. - 2017. - Rezhim dostupa: http://desktop.arcgis.com/ru/arcmap/10.3/manage-data/tin/fundamen-tals-of-tinsurfaces.htm. - Data dostupa : 02.06.2017.

10. The essentials of a TIN model [Elektronnyj resurs] // Introduc-tion to Spatial Analysis. - 2017. - Rezhim dostupa: http://planet.botany.uwc.ac.za/nis//GIS/spatial/chap_1_50.htm. - Data dostupa: 02.06.2017.

11. What's the point? Interpolation and extrapolation with a regular grid DEM [Elektronnyj resurs] // GeoComputation 99. - 1999. - Rezhim dostupa : http://www.geocomputation.org/1999/082/-gc_082.htm. - Data dostupa : 03.06.2017. 
12. Cifrovaya model' rel'efa [Elektronnyj resurs] // LidarWiki. - 2015. Rezhim dostupa : http://lidar.pro/wiki/Cifrovaya_model'_ ᄀrel'efa. - Data dostupa : 03.06.2017.

13. Eremin, M. A. Komp'yuternaya model' proryva Volzhskoj plotiny / M. A. Eremin, A. V. Hoperskov // Vestnik VolGU. Seriya 1: Matematika. Fizika. - 2006. - № 10. - S. 139-142.

14. Karepova E. D. Modelirovanie neustanovivshegosya dvizheniya vody $v$ nizhnem b'efe Boguchanskoj GES / E. D. Karepova, G. A. Fedorov // Vychislitel'nye tekhnologii. - 2008. - № S2. - S. 28-38.

15. Federal Guidelines for Inundation Mapping of Flood Risks Associated with Dam Incidents and Failures [Elektronnyj resurs] // FEMA. - 2013. Rezhim dostupa: https://www.fema.gov/media-library-data/96171edb98e3f51ff9684a8d1f034d97/Dam_Guidance_508.pdf. - Data dostupa : 12.02 .2017 .

16. Petrov, D. O. Algoritm vychisleniya granic oblasti zatopleniya dlya rechnoj seti s modelirovaniem rasprostraneniya vody po rastrovomu predstavleniyu rel'efa / D. O. Petrov, A. A. Volchek, D. A. Kostyuk // Doklady BGUIR. - 2016. - № 5 (99) - S. 73-78.

17. $K$ voprosu modelirovaniya i prognozirovaniya pavodkovoj situacii na meliorirovannyh zemlyah / D. O. Petrov, A. A. Volchek, D. A. Kostyuk, N. N. SHeshko // Ekologicheskoe sostoyanie prirodnoj sredy i nauchnoprakticheskie aspekty sovremennyh meliorativnyh tekhnologij: sb. nauch. tr. / FGBOU VPO RGATU. - Ryazan', 2012. - Vyp. 5. - S. 112-116.

18. Avtomatizirovannaya vizualizaciya pavodkovoj situacii / D. O. Petrov, A. A. Volchek, D. A. Kostyuk, N. N. SHeshko // Pryrodnae asyaroddze Palessya: asablivasci i perspektyvy razviccya: zb. navuk. prac / Paleski agrarna-ekalagichny instytut NAN Belarusi. - Brest: Al'ternativa, 2013. Vyp. 6. - S. 5-7.

19. Geoinformacionnyj analiz posledstvij katastroficheskih navodnenij po materialam DZZ / B. A. Novakovskij, O. N. Kolesnikova, A. I. Prasolova, R.V. Permyakov // Geomatika. - 2015. - № 2. - S. 52-56.

20. Guerin, S. Methodology used to determine coastal flooding due to sea level rise / S. Guerin, J. Thorp, N. Thompson // A Coastal Impact Study: Nation Under Siege. - 2007. - P. 25-31.

21. Assessment of inundation risk from sea level rise and storm surge in northeastern coastal national parks / A. Murdukhayeva, P. August, M. Bradley, C. LaBash, N. Shaw // Journal of Coastal Research. 2013. - Vol. 29. - № 6a. - P. 1-16.

22. Postnova, I. S. Tekhnologiya ocenki s pomoshch'yu GIS zon zatopleniya vesennimi pavodkami maloj obespechennosti / I. S. Postnova, S. G. YAkovchenko, V. O. Dmitriev // Vychislitel'nye tekhnologii : special'nyj vypusk: trudy mezhdunarodnoj konferencii i shkoly molodyh uchenyh "Vychislitel'no-informacionnye tekhnologii dlya nauk ob okruzhayushchej srede" (CITES 2005), Tomsk, 13-23 marta $2005 \mathrm{~g}$ : v 2 ch. - Tomsk, 2005. - CH. 2. - T. 10. - S. 39-46.

23. Opyt prognoza zon zatopleniya pri pavodkah i navodneniyah S. V. Serebryakov, A. N. Gushchin, M. E. Korshunov, V. V. Gusev // Geoprofi. - 2005. - № 5. - S. 53-55.

24. Serebryakov, S. V. Opyt sozdaniya geoinformacionnoj sistemy upravleniya riskami chrezvychajnyh situacij $v$ Sverdlovskoj oblasti I S. V. Serebryakov, V. V. Gusev, YU. D. Zraenko // Vestnik SGUGiT (Sibirskogo gosudarstvennogo universiteta geosistem i tekhnologij). 2010. - № 1 (12). - S. 139-144.

25. Horritt, M. S. A methodology for the validation of uncertain flood inundation models / M.S. Horrit //Journal of Hydrology. - 2006. - Vol. 326, № 1. - P. 153-165.

26. Alsynbaev, K. S. Razrabotka integrirovannoj sistemy monitoringa i prognozirovaniya ledovoj i pavodkovoj obstanovki na rekah avtonomnogo okruga na osnove operativnyh dannyh DZZ i gidropostov / K. S. Alsynbaev, YA. S. Sulyaev // YUgorskij nauchno-issledovatel'ski] institut informacionnyh tekhnologij: otchet za 2007 god. - Novosibirsk: Izd-vo SO RAN, 2008. - S. 35-39.
27. Vishnevskaya, I. A. Komp'yuternaya tekhnologiya ocenki zon zatopleniya pri navodneniyah: avtoref. dis. ... kand. tekhnich. nauk: 05.11.13 / I. A. Vishnevskaya; In-t prikladnoj geofiziki im. ak. E. K. Fedorova. - M., 2006. $-23 \mathrm{~s}$.

28. Mapping Coastal Inundation Primer // NOAA Coastal Services Center [Elektronnyj resurs]. - 2012. - Rezhim dostupa : https://coast.noaa.gov/digitalcoast/_pdf/guidebook.pdf. - Data dostupa : 21.05.2016.

29. Skvorcov, A. V. Algoritmy postroeniya triangulyacii s ogranicheniyami / A.V. Skvorcov // Vychislitel'nye metody i programmirovanie. - 2002. T. 3. - № 3. - S. 82-92.

30. HEC-RAS River Analysis System. User's Manual. Version $5.0 /$ G. W. Brunner // US Army Corps of Engineers Hydrologic Enginnering Center [Elektronnyj resurs]. - 2016. - Rezhim dostupa: http://www.hec.usace.army.mil/software/hec-ras/documentation/HECRAS\%205.0\%20Users\%20Manual.pdf. - Data dostupa : 19.05.2016.

31. Early Warning And On-Line Mapping For Flood Events / D. Mioc, B. Nickerson, F. Anton, E. MacGillivray, A. Morton, D. Fraser, P. Tang, A. Kam // Geoscience and Remote Sensing, New Achievements / ed. by D. Riccio, P. Imperatore. - INTECH Open Access Publisher, 2010. Ch. 9. - P. 147-162.

32. Flood simulation and visualization / M. Kollinger, K. Vondráček, V. Šeblová, J. Zdražil, J. Jirka, L. Vokounová // Central European Seminar on Computer Graphics. Slovakia. - 2003.

33. Modul' rascheta zatopleniya territorii dlya sistemy monito-ringa i prognozirovaniya pavodka / D. O. Petrov, A. A. Volchek, D. A. Kostyuk, N. N. SHeshko // Vestnik BrGTU. Seriya fizika, ma-tematika, informatika. - 2011. - №5 (71). - S. 43-45.

34. Geometrichna vizualizaciya zoni zatoplennya dlya sistemi monitoringu i prognozuvannya pavodku / D. O. Petrov, V. V. Vishnivs'kij, O. O. Volchek, D. O. Kostyuk // Telekomunikacijni ta informacijni tekhnologiï. 2016. - №2. - S. 27-32.

35. Vizualizaciya gidrologicheskoj obstanovki $\mathrm{v}$ bassejnah krupnyh rek sredstvami GIS-tekhnologij / S. V. Borshch, T. E. Samsonov, YU. A. Simonov, E. A. L'vovskaya // Trudy Gidrometeorologicheskogo nauchno-issledovatel'skogo centra Rossijskoj Federacii. - 2013. № 349. - S. 47-62.

36. Sistema rascheta i vizualizaciya zony zatopleniya na osnove kletochnogo avtomata / D. O. Petrov, A. A. Volchek, D. A. Kostyuk, N. N. SHeshko // Aktual'nye problemy nauk o Zemle: ispol'zovanie prirodnyh resursov i sohranenie okruzhayushchej sredy: sb. materialov mezhdunar. nauch.-prakt. konf., posvyashch. godu nauki v Resp. Belarus': v 2 ch., Brest, 25 - 27 sent. 2017 g. I In-t prirodopol'zovaniya NAN Belarusi, Brest. gos. un-t im. A. S. Pushkina, Brest. gos. tekhn. un-t ; redkol.: A. K. Karabanov [i dr.] ; nauch. red. A. K. Karabanov, M. A. Bogdasarov. - Brest: BrGU, 2017. - CH. 1. - S. 145-148.

37. Petrov, D. O. Ocenka adekvatnosti primeneniya geometricheskih metodov dlya postroeniya zony zatopleniya pojm ravninnyh rek / D. O. Petrov, A. A. Volchek // Turisticheskij i prirodnyj potencial vodnyh ob"ektov belorussko-pol'skogo pogranich'ya: materialy nauch.-prakt. konferencii (Brest, 30-31 oktyabrya 2020 goda) / gl. red. N. V. Mihal'chuk - Brest : Al'ternativa, 2020. - S. 127-130.

Материал поступил в редакцию 10.03.2021 